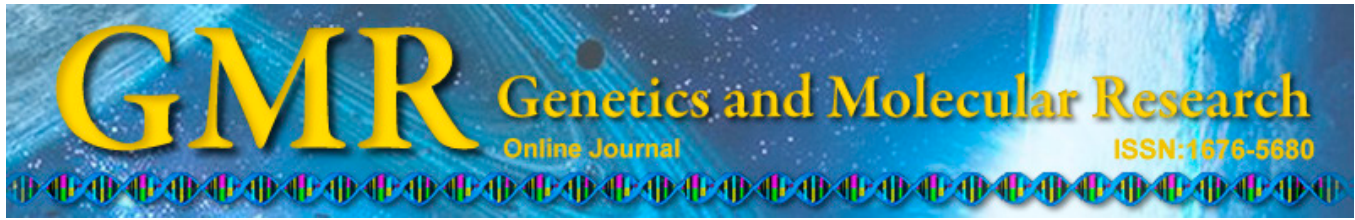

\title{
Characterization and phylogenetic analysis of the swine leukocyte antigen 3 gene from Korean native pigs
}

\author{
H.Y. Chung, Y.C. Choi and H.N. Park \\ Suwon, Korea \\ Corresponding author: H.Y. Chung \\ E-mail: chung133@korea.kr \\ Genet. Mol. Res. 14 (2): 5270-5279 (2015) \\ Received May 22, 2014 \\ Accepted January 19, 2015 \\ Published May 18, 2015 \\ DOI http://dx.doi.org/10.4238/2015.May.18.19
}

Animal Genomics Bioinformatics Division, National Institute of Animal Science,

\begin{abstract}
We investigated the phylogenetic relationships between pig breeds, compared the genetic similarity between humans and pigs, and provided basic genetic information on Korean native pigs (KNPs), using genetic variants of the swine leukocyte antigen 3 (SLA3) gene. Primers were based on sequences from GenBank (accession Nos. AF464010 and AF464009). Polymerase chain reaction analysis amplified approximately 1727 bp of segments, which contained $1086 \mathrm{bp}$ of coding regions and $641 \mathrm{bp}$ of the $3^{\prime}$ - and 5'-untranslated regions. Bacterial artificial chromosome clones of miniature pigs were used for sequencing the $S L A-3$ genomic region, which was 3114 $\mathrm{bp}$ in total length, including the coding (1086 bp) and non-coding (2028 bp) regions. Sequence analysis detected 53 single nucleotide polymorphisms (SNPs), based on a minor allele frequency greater than 0.01 , which is low compared with other pig breeds, and the results suggest that there is low genetic variability in KNPs. Comparative analysis revealed that humans possess approximately three times more genetic variation than do pigs. Approximately $71 \%$ of SNPs in exons 2 and 3 were detected in KNPs, and exon 5 in humans is a
\end{abstract}


highly polymorphic region. Newly identified sequences of $S L A-3$ using KNPs were submitted to GenBank (accession No. DQ992512-18). Cluster analysis revealed that KNPs were grouped according to three major alleles: SLA-3*0502 (DQ992518), SLA-3*0302 (DQ992513 and DQ992516), and SLA-3*0303 (DQ992512, DQ992514, DQ992515, and DQ992517). Alignments revealed that humans have a relatively close genetic relationship with pigs and chimpanzees. The information provided by this study may be useful in KNP management.

Key words: $S L A-3$; $M H C$ class I; Single nucleotide polymorphism; Korean native pig

\section{INTRODUCTION}

As candidate organ materials, porcine tissues have been issued in the medical sciences because of the similarities in organ size and immune systems between pigs and humans (Ando et al., 2003). Smith et al. (2004) attempted to overcome the problems of human immune responses to organ and cell transplantation, and disease resistance, based on genetic variations. However, due to the complexity of immune responses, as well as the huge amount of genetic variation within $M H C$ regions, this has not been entirely successful. In addition, comparisons of genetic polymorphisms between pigs ( $S L A)$ and humans ( $H L A$ class I genes) are crucial in understanding the mechanisms involved in $S L A$-mediated responses during organ transplantation.

$S L A$ class I (SLA-1, SLA-2, and SLA-3) genes on the pig chromosome 7q11-14 (Smith et al., 1995; Barbosa et al., 2004) are expressed on the surface of most nucleated cells, and are recognized by CD8+ cells (Charon et al., 2000; Ando et al., 2003). Approximately $4600 \mathrm{MHC}$ alleles have been detected in humans (Robinson et al., 2003), according to the 2.27.1 release of the International ImMunoGeneTics RNA database (http://www.imgt.org/), and a few alleles have been detected in pigs (Renard et al., 2001; Shigenari et al., 2004). Due to significantly high mutation rates in SLA genes, genetic variants are crucial for identifying haplotypes regarding phylogenetic relationships within and between breeds. Therefore, sequence analysis using whole mRNA and genomic DNA should ascertain the precise individual genotypes and identify $S L A$ genes.

Miniature pigs (MIPs) are excellent experimental animal models, and are ideal for studying SLA genotypes and alleles (Rothschild et al., 1984; Mallard et al., 1989). The Korean native pig (KNP) can be used as an animal model, even though its genetic variability has not been completely verified. Therefore, to use KNP in a study requires the detailed genetic information of individual pigs. Only one study has reported genetic variants of the SLA-3 gene using KNPs (Woo et al., 2005), but full genetic information should be verified for both coding and non-coding regions. According to previous studies, the HLA polymorphism is informative in identifying individual differences, as well as migration events, between species, based on the interpretation of allelic distributions that are considered as equidistant molecular units (Robinson et al., 2003; Barbosa et al., 2004). Therefore, this study investigated the genetic variants of the $S L A-3$ gene, in order to identify genetic differences between humans and pigs, to estimate genetic relationships between species, and to elucidate KNP SLA-3 alleles regarding the use of the KNP as an animal model. 


\title{
MATERIAL AND METHODS
}

\begin{abstract}
Animals
All of the experimental procedures and animals were approved by the Ethics and Welfare Committee of National Institute of Animal Science (NIAS), Korea. A total of $60 \mathrm{KNPs}$, without any significant genetic relationships existing between individuals according to pedigree analysis (with an inbreeding coefficient lower than 0.01), were selected and slaughtered at 30 weeks of age. Spleen tissue was immediately collected and transferred to the laboratory, using a stainless-steel container filled with liquid nitrogen. The samples were stored at $-70^{\circ} \mathrm{C}$ until the extraction of total RNA. Due to the high sequence similarity between genes in the $S L A$ class I region, MIP bacterial artificial chromosome (BAC) clones were used to define exon order, and the length of the entire $S L A-3$ gene. Briefly, 288,000 BAC clones, which were $110 \mathrm{~kb}$ long on average (corresponding to $10 \mathrm{X}$ coverage), had been previously constructed using 6 National Institute of Health (NIH, USA) MIPs. A four-dimensional selection system was adopted to select appropriate BAC clones that contained the SLA-3 gene.
\end{abstract}

\section{Selection of primers for cDNA and BAC clones}

The primers were designed based on cDNA sequences in GenBank (accession Nos. AF464009 and AF464010) to amplify the entire $S L A-3$ coding regions, with $60 \%$ GC content and an optimal temperature of $57^{\circ} \mathrm{C}$. The outer forward and reverse primers were AGCGC CACCG CGGTT CGCGG TTC (nucleotide positions 2 to 24), and AGAAG CAATT TTTAT TCTTG CAC (nucleotide positions 1707 to 1729), respectively. After successful amplifications, inner primers were re-designed to confirm the $S L A-3$ gene as CCTAC GACGG CGCSG ATTA (forward nucleotide positions 495 to 513) and TTTCA GAGGC AGCTG CAGAA A (reverse nucleotide positions 1247 to 1266). The nucleotide positions were based on cDNA sequences (accession No. DQ992512) that were generated from this study using KNPs. Primer sets were used to screen both genomic regions of the $S L A-3$ gene for MIP BAC clones and cDNAs of the KNPs.

\section{cDNA analysis}

For the extraction of total RNA, TRizol ${ }^{\circledR}$ (Life Technologies, Shanghai, China) was added to $2 \mathrm{~g}$ tissue sample (2-3-mm cubes) with liquid nitrogen, and the tissues were homogenized. The first strand was synthesized by random primers using $5 \mathrm{X}$ First-Strand buffer, $0.1 \mathrm{M}$ dithiothreitol, and SuperScript ${ }^{\mathrm{TM}} \mathrm{III}$ Reverse Transcriptase (Invitrogen) at $25^{\circ} \mathrm{C}$ for 5 $\min , 50^{\circ} \mathrm{C}$ for $2 \mathrm{~h}$, and $70^{\circ} \mathrm{C}$ for $15 \mathrm{~min}$. The final volume $(25 \mu \mathrm{L})$ consisted of $2.5 \mu \mathrm{L} 10 \mathrm{X}$ reaction buffer (10 mM Tris, $\mathrm{pH}, 8.3,50 \mathrm{mM} \mathrm{KCl}, 0.1 \%$ Triton X-100, and $1.5 \mathrm{mM} \mathrm{MgCl}$ ), $25 \mathrm{mM}$ dNTP, $10 \mathrm{pM}$ of each primer, $50 \mathrm{ng}$ cDNA, and $0.2 \mathrm{U}$ Taq DNA polymerase (Gibco BRL, Grand Island, NY, USA). The amplification included 35 cycles, with the following steps: denaturation at $94^{\circ} \mathrm{C}$ for $1 \mathrm{~min}$, annealing at $57^{\circ} \mathrm{C}$ for $1 \mathrm{~min}$, and polymerization at $72^{\circ} \mathrm{C}$ for 2 min (MJ Research, PT-200, Watertown, MA, USA). Approximately 1728-bp segments on $1.2 \%$ agarose gel were purified and cloned into a pGEM $^{\circledR} \mathrm{T}$ Easy vector (Promega, Madison, WI, USA) at $4^{\circ} \mathrm{C}$ overnight. The transformation was conducted using DH10B competent cells to produce several copies of the $S L A-3$ segments. At least four clones from each individual 
were collected for sequence analysis to minimize reading errors; therefore, a total of 315 clones were used to identify SNPs in the coding regions, using an ABI 3730XL Genetic Analyzer (Applied Biosystems, Foster City, CA, USA) and T7 and SP6 universal primers.

\section{Analysis of shotgun clones}

Four-dimensional screening systems selected six candidate clones from 288,000 MIP BAC clones with the outer and inner primers, using a $20-\mu \mathrm{L}$ mixture that contained $2 \mu \mathrm{L} 10 \mathrm{X}$ reaction buffer, $25 \mathrm{mM}$ dNTP, $1 \mu \mathrm{L}$ of each primer $(10 \mathrm{pM})$, and $2 \mathrm{U}$ Taq polymerase. A total of 35 cycles were included, with the following steps: denaturation at $94^{\circ} \mathrm{C}$ for $1 \mathrm{~min}$, annealing at $52^{\circ} \mathrm{C}$ for $1 \mathrm{~min}$, and polymerization at $72^{\circ} \mathrm{C}$ for $1.5 \mathrm{~min}$. After the successful screening of six BAC clones that were grown in lysogeny broth media with $1 \%$ chloramphenicol $(25$ $\mathrm{mg} / \mathrm{L}$ ), the BAC DNA was shared by ultra-sonication procedures in water for $5 \mathrm{~s}$, followed by the extermination of genomic DNA for $16 \mathrm{~h}$ with a Large-Construct Kit (Qiagen). A 20- $\mu \mathrm{L}$ mixture containing $17 \mu \mathrm{L}$ DNA, $2 \mu \mathrm{L}$ 10X Blunting Kination Buffer, and $1 \mu \mathrm{L}$ enzyme (TaKaRa Blunting Kination Ligation Reagent Set) was incubated at $37^{\circ} \mathrm{C}$ for $10 \mathrm{~min}$ and ligated into a vector (PUC $118 / \mathrm{SmaI}$ restricted) with $18 \mu \mathrm{L}$ ligation buffer at $16^{\circ} \mathrm{C}$ overnight. Transformation was conducted with the DH10B competent cells and produced approximately 2100 shotgun clones that were sequenced with M13 universal primers.

\section{Sequencing and phylogenetic analysis}

To verify the boundary between coding and non-coding regions, alignments were performed with 315 cDNA sequences from the spleen tissues of KNPs, and genomic DNA sequences from 2100 shotgun clones of MIP BACs, using the SeqMan software (DNASTAR version 6.0; http://www.dnastar.com/t-nextgen-seqman-ngen.aspx). The newly confirmed and identified KNP sequences were submitted to GenBank with accession numbers, according to the unique positions of the nucleotides. A phylogenetic tree was constructed using DNAdist (DNA distance matrix, Bio-edit version 7.0.1) with the full-length cDNA of the $S L A-3$ gene and the 29 previously reported $S L A-3$ alleles from GenBank. Pedigree analysis confirmed the segregations of the identified alleles using six KNP half-sib families. Seven animal taxa (human, pig, monkey, horse, chimpanzee, cattle, and mouse) with 230 accession numbers $(99,50,11,16,8,17$, and 29, respectively) from GenBank were used to compare the sequence identities (Table 1). The frequencies of SNPs, alleles, and the minor allele frequency (MAF) and information content were estimated using Arlequin version 3.5 (http://cmpg.unibe.ch/software/arlequin35/).

\section{RESULTS}

\section{MIP BAC clones}

The four-dimensional screening procedure identified six candidate BAC clones that contained whole sequences of the $S L A-3$ gene, which were $3114 \mathrm{bp}$ in length. The sequence analysis, with an average of 410 shotgun clones for each BAC clone (corresponding to $10 \mathrm{X}$ coverage), determined the coding (1086 bp) and non-coding (2028 bp) regions. In addition, alignments confirmed the exon boundaries, resulting in eight coding regions with an average length of $135.75 \mathrm{bp}$, and an average length of $298.57 \mathrm{bp}$ for non-coding regions (Table 2). 
H.Y. Chung et al.

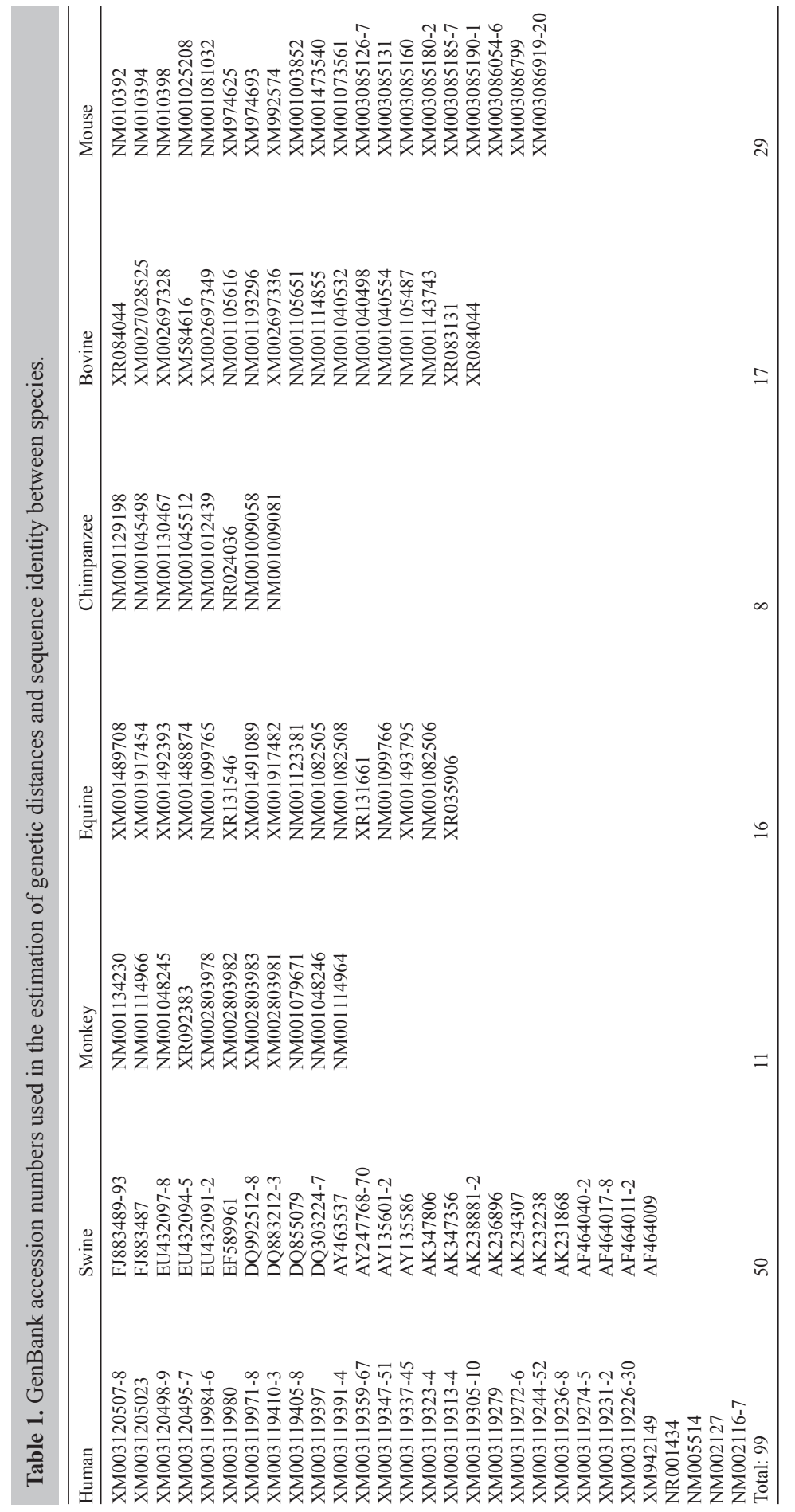


Phylogenetic analysis of $S L A-3$

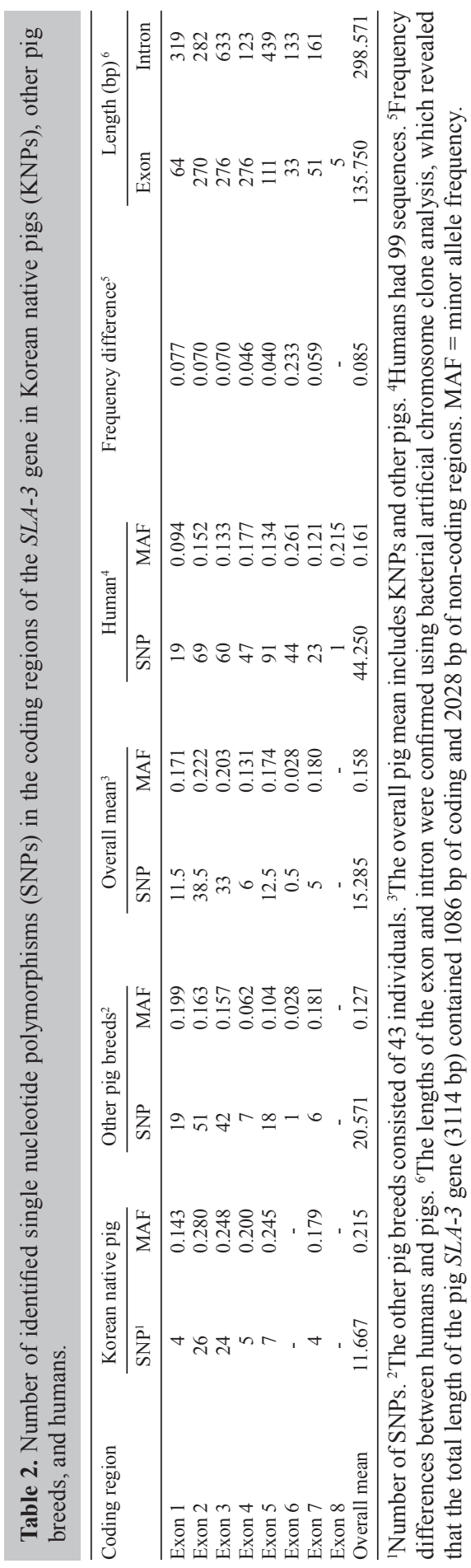




\section{Analysis of cDNA sequences}

The analysis (using the outer primers) amplified the cDNA fragments of the SLA-3 gene, resulting in $1728 \mathrm{bp}$ of product. Comparisons of the individual sequences confirmed that the length of the coding regions (based on the GenBank accession No. DQ992512) was 1086 bp. Alignments ascertained that the coding region started and ended at nucleotide positions 83 and 1168, respectively. The newly identified sequences for each individual, showing the unique locations of SNPs, were submitted to GenBank with the accession No. DQ992512-8.

Sequence analysis revealed that KNPs were clustered in the $S L A-3 * 0502$ (DQ992518), SLA-3*0302 (DQ992513 and DQ992516), and SLA-3*0303 (DQ992512, DQ992514, DQ992515, and DQ992517) alleles in terms of sequence identity, based on sequences from the Immuno Polymorphism Database (IPD; http://www.ebi.ac.uk/ipd/). As shown in Table 2, alignments for cDNA detected an average of 11.667 SNPs for the coding regions in KNPs, while other pig breeds and humans had an average of 20.571 and 44.250 SNPs, respectively. Numerous SNPs, across all of the coding regions in KNPs, were observed between exon numbers 2 and 3, which covered approximately $71 \%$ of the entire SNPs, whereas exons 6 and 8 did not exhibit any variation. However, a genetic variant from nucleotide position 1104 was observed at exon number 6 in the $S L A-3 * 03 \operatorname{cs} 01$ allele in the Meishan pig. In humans, SNPs were detected in all coding regions. Estimations of the MAF of each SNP in the KNP coding regions revealed that it was 0.215 , which was higher than that in other pig breeds $(0.127)$ and humans (0.162). These results suggest that the genetic variability of KNP was as high as in a natural population. An interesting finding was that humans had a higher mean number of SNPs (44.250) than did pigs (15.285); this may have been caused by artificial selection in pigs.

Fifty-three of 150 SNPs were selected based on an MAF that was greater than 0.1 (Table 3), and the average MAF for each SNP position was estimated to be 0.366 for KNPs. Approximately $70 \%$ SNPs with an MAF lower than 0.1 were not used for further analysis, in order to avoid biased estimations. The highest (0.406) and lowest $(0.333)$ MAFs were observed at nucleotide positions 1408 and 960 in the 3'-untranslated region, respectively.

Table 3. Number of identified single nucleotide polymorphisms (SNPs) in the SLA-3 gene generated from Korean native pig and Korean Jeju pig spleen tissues.

\begin{tabular}{|c|c|c|c|c|c|c|c|c|c|c|c|c|c|c|c|}
\hline $\mathrm{LOC}^{1}$ & SNP & MAF & IC & $\mathrm{LOC}^{1}$ & SNP & MAF & IC & $\mathrm{LOC}^{1}$ & SNP & MAF & IC & $\mathrm{LOC}^{1}$ & SNP & MAF & IC \\
\hline 60 & $\mathrm{C} / \mathrm{T}$ & 377 & 663 & 60 & $\mathrm{G} / \mathrm{A}$ & 366 & 657 & 68 & $\mathrm{~A} / \mathrm{G}$ & 0.40 & 0.692 & 133 & $\mathrm{C} / \mathrm{T}$ & 0.338 & 0.656 \\
\hline 66 & $\mathrm{~T} / \mathrm{C}$ & 01 & 673 & 63 & $\mathrm{G} / \mathrm{A}$ & 66 & 657 & & $\mathrm{~T} / \mathrm{G}$ & 67 & 4 & 342 & $\mathrm{~T} / \mathrm{C}$ & & .656 \\
\hline 67 & $\mathrm{C} / \mathrm{T}$ & 04 & 0.675 & 372 & $\mathrm{C} / \mathrm{G}$ & 344 & 0.641 & & $\mathrm{~A} / \mathrm{G}$ & 69 & 58 & 51 & $\mathrm{C} / \mathrm{T}$ & & .678 \\
\hline 286 & $\mathrm{~T} / \mathrm{G}$ & 0.404 & 0.675 & 373 & $\mathrm{~T} / \mathrm{A}$ & 0.340 & 0.658 & 75 & $\mathrm{~T} / \mathrm{C}$ & 66 & 0.746 & 1400 & $\mathrm{~A} / \mathrm{G}$ & & 0.675 \\
\hline 291 & $\mathrm{~T} / \mathrm{C}$ & 0.404 & 0.675 & 375 & $\mathrm{~T} / \mathrm{A}$ & 0.366 & 0.657 & 960 & $\mathrm{C} / \mathrm{T}$ & 0.333 & 0.651 & 1404 & $\mathrm{G} / \mathrm{T}$ & 0.343 & 0.641 \\
\hline 294 & $\mathrm{C} / \mathrm{A}$ & 0.342 & 0.641 & 437 & $\mathrm{C} / \mathrm{A}$ & 0.336 & 0.672 & 991 & $\mathrm{C} / \mathrm{A}$ & 0.354 & 0.792 & 1408 & $\mathrm{~A} / \mathrm{G}$ & 406 & 0.676 \\
\hline 302 & G/A & 0.341 & 0.785 & 445 & $\mathrm{C} / \mathrm{A}$ & 0.338 & 0.656 & 998 & $\mathrm{C} / \mathrm{A}$ & & 0.792 & 1474 & G/A & & 0.639 \\
\hline 305 & $\mathrm{C} / \mathrm{A}$ & 0.378 & 0.680 & 524 & $\mathrm{C} / \mathrm{A}$ & 0.343 & 0.641 & 1005 & $\mathrm{G} / \mathrm{A}$ & 0.351 & 0.791 & 1481 & $\mathrm{G} / \mathrm{A}$ & & 0.657 \\
\hline 328 & $\mathrm{G} / \mathrm{C}$ & 0.338 & 0.656 & 601 & $\mathrm{C} / \mathrm{G}$ & 0.389 & 0.225 & 1049 & $\mathrm{C} / \mathrm{T}$ & 0.354 & 0.792 & 1519 & $\mathrm{~T} / \mathrm{C}$ & & 0.663 \\
\hline 338 & $\mathrm{G} / \mathrm{C}$ & 0.367 & 0.674 & 610 & $\mathrm{~T} / \mathrm{C}$ & 0.404 & 0.675 & 1145 & $\mathrm{~T} / \mathrm{C}$ & & 0.641 & 1570 & $\mathrm{G} / \mathrm{A}$ & 0.405 & 0.692 \\
\hline 339 & $\mathrm{~A} / \mathrm{G}$ & 0.367 & 0.674 & 614 & $\mathrm{~T} / \mathrm{C}$ & 0.404 & 0.675 & 1226 & $\mathrm{C} / \mathrm{T}$ & 0.3 & 0.641 & 1603 & $\mathrm{~T} / \mathrm{G}$ & 0.405 & 0.692 \\
\hline 353 & $\mathrm{G} / \mathrm{A}$ & 0.366 & 0.657 & 654 & $\mathrm{~T} / \mathrm{A}$ & 0.366 & 0.65 & 1280 & $\mathrm{G} / \mathrm{T}$ & 0.369 & 0.658 & & & & \\
\hline 35 & $\mathrm{C} / \mathrm{G}$ & & 0.657 & 674 & $\mathrm{G} / \mathrm{T}$ & 0227 & 0.639 & 1302 & $\mathrm{~A} / \mathrm{C}$ & & 0.707 & & & & \\
\hline 357 & $\mathrm{~T} / \mathrm{A}$ & 0.366 & 0.657 & 675 & $\mathrm{~A} / \mathrm{T}$ & 0.338 & 0.656 & 1311 & $\mathrm{~T} / \mathrm{G}$ & 0.403 & 0.708 & AVG & & 0.366 & 0.669 \\
\hline
\end{tabular}

${ }^{1} \mathrm{LOC}=$ nucleotide positions based on sequences $(\mathrm{DQ992512}) ; \mathrm{MAF}=$ minor allele frequency $=\mathrm{IC}=$ information content. $\mathrm{AVG}=$ average. 


\section{Genetic relationships}

The consensus sequences of the SLA-3 gene were compared between taxa to investigate genetic differences and identities. The calculation of the sequence identity revealed that humans exhibit a relatively high sequence identity with chimpanzees (0.633), MIPs (0.648), and KNPs (0.631), while having the lowest value (0.454) with horses, which had the lowest sequence identity of all the taxa (Table 4). The main result was that the averaged swine, which consisted of 43 breeds and accession numbers from GenBank, presented relatively less sequence identity with MIPs (0.902) and KNPs (0.934), even though high values (greater than 0.950 ) were expected due to the genetic similarity between the same pig breeds. In addition, MIPs had a relatively higher sequence identity with KNPs (0.932) than with the averaged swine breed (0.902), which was surprising, because the KNPs had been managed as a natural breed, whereas the MIPs were part of a closed population.

Table 4. Sequence identity of the $S L A-3$ gene between species.

\begin{tabular}{|c|c|c|c|c|c|c|c|c|}
\hline & Monkey ${ }^{1}$ & Equine $^{2}$ & Chimpanzee $^{3}$ & Bovine $^{4}$ & Mouse $^{5}$ & Human $^{6}$ & Swine $^{7}$ & $\mathrm{KNP}^{8}$ \\
\hline Equine & 0.422 & & & & & & & \\
\hline Chimpanzee & 0.606 & 0.435 & & & & & & \\
\hline Bovine & 0.476 & 0.422 & 0.473 & & & & & \\
\hline Mouse & 0.472 & 0.397 & 0.468 & 0.447 & & & & \\
\hline Human & 0.594 & 0.454 & 0.633 & 0.467 & 0.481 & & & \\
\hline Swine & 0.571 & 0.454 & 0.588 & 0.553 & 0.521 & 0.613 & & \\
\hline KNP & 0.568 & 0.452 & 0.587 & 0.565 & 0.522 & 0.631 & 0.934 & \\
\hline MIP $^{9}$ & 0.577 & 0.448 & 0.587 & 0.561 & 0.533 & 0.648 & 0.902 & 0.932 \\
\hline
\end{tabular}

${ }^{1}$ Monkey consisted of 11 accession numbers. ${ }^{2}$ Equine consisted of 16 accession numbers. ${ }^{3}$ Chimpanzee consisted of 8 accession numbers. ${ }^{4}$ Bovine consisted of 17 accession numbers. ${ }^{5}$ Mouse consisted of 29 accession numbers. ${ }^{6} \mathrm{Human}$ consisted of 99 accession numbers. ${ }^{7}$ Swine consisted of 43 accession numbers, except KNP. ${ }^{8} \mathrm{KNP}$ consisted of 7 accession numbers. ${ }^{9} \mathrm{MIP}$ consisted of 6 individuals that were used to construct bacterial artificial chromosome clones. The sequence identity was estimated using a sequence identity matrix (BioEdit version 7.0.1). KNP = Korean native pig; MIP = miniature pig.

Figure 1 presents the genetic relationships between the 29 previously defined SLA-3 alleles from GenBank and the newly identified KNP $S L A-3$, with three major clusters harboring in the $S L A-3 * 0302, S L A-3 * 0502$, and $S L A-3 * 0303$ alleles. The previously determined allele $(S L A-3 * k n 02)$ using Korean pigs exhibited a close genetic relationship with KNPs (DQ992511, DQ992513, and DQ992516). According to the nomenclature of SLA-3 in the IPD (http://www. ebi.ac.uk/cgi-bin/ipd/mhc/view_nomenclature.cgi?sla.3), KNPs (DQ992512, DQ992514, DQ992515, and DQ992517) were placed in the $S L A-3 * 0303$ allele, while DQ992518 was placed in the $S L A-3 * 0502$ allele.

\section{DISCUSSION}

The low genetic variability of KNPs was expected because their commercial unpopularity may have caused a high level of inbreeding in the population and because no new genetic material has been introduced. Alternatively, the low genetic variability may have been caused by the small sample size. However, this can be ignored, because the selection of KNPs was based on different sire lines that had inbreeding coefficients lower than 0.01 . In addition, KNPs have characteristics such as a small body size, low feed efficiency, and low growth 


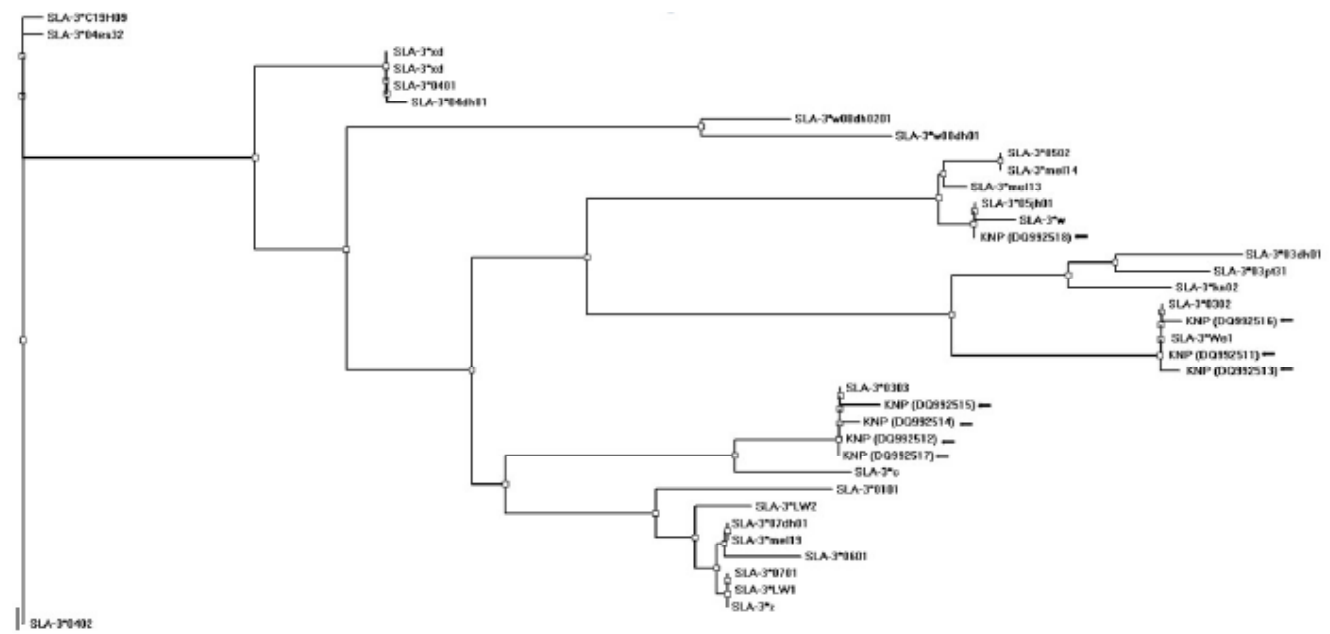

Figure 1. Phylogenetic analysis of $S L A-3$ sequences among 29 major representative alleles in Korean native pigs (KNPs) (DQ992512-8) and miniature pigs (MIPs). Representative SLA-3 alleles were used with GenBank accession numbers as SLA-3*0502 (EU432094), SLA-3*mel14 (AF464041), SLA-3*mel13 (AY135601), SLA$3 * 05 j h 01$ (DQ883213), SLA-3*w (AF464012), SLA-3*03dh01 (FJ883487), SLA-3*03pt31 (EU432095), SLA$3 * k n 02$ (DQ855079), SLA-3*0302 (EU432097), SLA-3*We1 (AY247768), SLA-3*0303 (EF589961), SLA$3 *_{c}$ (AF464018), SLA-3*w08dh0201 (FJ883493), SLA-3*w08dh01 (FJ883491), SLA-3*04dh01 (FJ883490), SLA-3*0401 (DQ303225), SLA-3*xd (AY135602), SLA-3*xd (AF464017), SLA-3*04es32 (EU432098), SLA$3 * C 19 H 09$ (AY135586), SLA-3*0402 (EU432092), SLA-3*0101 (DQ303224), SLA-3*LW2 (AY247770), SLA$3 * 07 d h 01$ (FJ883489), SLA-3*mel19 (AF464040), SLA-3*0601 (EU432091), SLA-3*0701 (DQ883212), SLA$3 * L W 1$ (AY247769), and $S L A-3 * z$ (AF464009). Genetic distances between alleles were estimated using DNAdist (DNA distance matrix, Bio-edit version 7.0.1). Four groups of human consensus sequences were constructed with 99 accession numbers.

rates compared to commercial pig breeds (e.g., Duroc, Landrace, or Yorkshire). In general, small populations can accelerate gene fixations if no genetic materials have been added to the population for a long time. Therefore, the results of this study, with genetic variations of the $S L A-3$ gene, may indicate that KNP gene fixations have been activated for many years. The numerical evidence from this study supports the above statement, that the average number of SNPs in KNPs (11.667) was lower than in other animals, as shown in Table 2. Since the low genetic variability of KNPs has been confirmed, the determination of possible uses of KNPs for constructing an animal model should have the advantage of standardizing genetic variability regarding the $S L A-3$ gene, as well as other genes within the $S L A$ region.

In general, SLA nomenclature requires the naming of new SLA alleles that have complete sequences of exons 2 and 3 and are known as highly variable and conserved regions (Smith et al., 2004). The present results agreed the statement with locating approximately $71 \%$ of SNPs in these regions for all breeds. In addition, exons 1 and 5 presented approximately $22.4 \%$ of SNP in the coding regions, and the result may be a secondary issue for using the identified SNPs in animal identification as genetic markers. Comparisons of genetic variability in exons 2 and 3 between humans and pigs revealed that the number of SNPs in humans was twice as high as that in pigs, whereas the SNP frequencies in these regions in humans were lower than in pigs. This result is complicated in terms of genetic evolution, but it is possible that humans 
exhibit greater genetic diversity than do pigs, but genetic variants and genes are highly fixed if the number of sequences used in this analysis were not considered as major effects.

KNPs were successfully characterized in terms of alleles, with limited genetic information of $S L A-3$ sequences and alleles. Based on sequence comparisons and phylogenetic analysis (Figure 1), the KNP $S L A-3$ gene relationships were significantly different from most European and Western pig breeds and alleles $(S L A-3 * 3 x d$ and $S L A-3 * L W)$, indicating that KNPs have been districted (see Woo et al., 2005). Therefore, the SLA-3 sequence information provided by this study may provide useful information for further genetic analysis regarding the management of KNPs, in order to fix the $S L A$ genotypes. In conclusion, this study provides newly discovered sequence information and genetic characteristics of the $S L A-3$ gene and alleles in KNPs, and the nucleotide sequences can be used for developing an SLA genotyping protocol. The results reported here will serve as a reference for the KNP SLA-3 gene that can be used for animal models based on the requirements of gene fixation.

\section{ACKNOWLEDGMENTS}

Research supported in part by governmental funds appropriated to the Rural Development Administration (RDA), Korea, and was a contributing project for the National Institute of Animal Science (Regional Project \#PJ010220).

\section{REFERENCES}

Ando A, Kawata H, Shigenari A, Anzai T, et al. (2003). Genetic polymorphism of the swine major histocompatibility complex (SLA) class I genes, SLA-1, -2 and -3. Immunogenetics 55: 583-593.

Barbosa A, Demeure O, Urien C, Milan D, et al. (2004). A physical map of large segments of pig chromosome 7q11-q14: comparative analysis with human chromosome 6p21. Mamm. Genome 15: 982-995.

Charon P, Renard C, Gaillard CR and Vaiman M (2000). The porcine major histocompatibility complex and related paralogous regions: a review. Genet. Sel. Evol. 32: 109-128.

Mallard BA, Wilkie BN and Kennedy BW (1989). Influence of major histocompatibility genes on serum hemolytic complement activity in miniature swine. Am. J. Vet. Res. 50: 359-363.

Renard C, Vaiman M, Chiannilkulchai N, Cattolico L, et al. (2001). Sequence of the pig major histocompatibility region containing the classical class I genes. Immunogenetics 53: 490-500.

Robinson T, Waller MJ, Parham P, Groot D, et al. (2003). IMGT/HLA and IMGT/MHC sequence database for the study of the major histocompatibility complex. Nucleic Acids Res. 31: 311-314.

Rothschild MF, Chen HL and Christian LL (1984). Breed and swine lymphocyte antigen haplotype differences in agglutination titers following vaccination with B. bronchiseptica. J. Anim. Sci. 59: 643-649.

Shigenari A, Ando A and Renard C (2004). Nucleotide sequencing analysis of the swine 433-kb genomic segment located between the non-classical and classical SLA class I gene clusters. Immunogenetics 55: 695-704.

Smith DM, Lunney JK, Martens GW, Ando A, et al. (2004). Nomenclature for factors of the SLA class-I system. Tissue Antigens 65: 136-149.

Smith TP, Rohrer GA and Alexander LJ (1995). Directed integration of the physical and genetic linkage maps of swine chromosome 7 reveals that the SLA spans the centromere. Genome Res. 5: 259-271.

Woo CJ, Kang IY, Yun HI, Dirisala VR, et al. (2005). Molecular cloning and analysis of allelic variation of the SLA-3 gene in Korean native pigs. Korean J. Genet. 27: 337-343. 